\title{
Thirty months' experience with cyclosporin in human pancreatic transplantation
}

\author{
J. Traeger ${ }^{1}$, E. Bosi ${ }^{2}$, J. M. Dubernard ${ }^{1}$, J. L. Touraine ${ }^{1}$, P. M. Piatti ${ }^{2}$, A. Secchi ${ }^{2}$, A. Gelet ${ }^{1}$ and G. Pozza ${ }^{2}$ \\ ${ }^{1}$ Clinique de Nephrologie et Maladies Métaboliques, Service d'Urologie, INSERM U 80, Hôpital Edouard Herriot, Lyon, France, and \\ ${ }^{2}$ Clinica Medica VIII, Istituto Scientifico San Raffaele, University of Milan, Italy
}

\begin{abstract}
Summary. Between September 1978 and December 1983, 33 simultaneous kidney plus pancreatic transplantations were performed in Type 1 (insulin-dependent) diabetic patients with uraemia at the Herriot Hospital, Lyon. In eight patients grafted before June 1981, immunosuppressive treatment consisted of azathioprine, steroids and a temporary course with anti-lymphocyte globulins (protocol A). Since June 1981, the immunosuppressive treatment has consisted of cyclosporin administered according to two protocols: from the day of transplantation with temporary anti-lymphocyte globulins with or without steroids (protocol B, seven patients), or after
\end{abstract}

an initial course with protocol $\mathrm{A}$, with or without steroids (protocol C, 18 patients). Only slight differences in patient and pancreatic graft survival between the three protocols were observed at 3,6 and 12 months, while an improved survival rate for both patients and pancreatic grafts was observed in protocols $\mathrm{B}$ and $\mathrm{C}$ at 2 years. Moreover the incidence of pancreatic rejection as a cause of loss of pancreatic function seemed to be reduced under protocols $B$ and $C$.

Key words: Type 1 diabetes, cyclosporin, pancreatic transplantation, renal transplantation, immunosuppression.
Cyclosporin, also referred to as cyclosporin A or cyclosporine, is a cyclic polypeptide of fungal origin, composed of 11 amino-acid residues, with a potent suppressive activity on both cell-mediated and humoral immunity. Although the mechanism of action has not yet been completely clarified, it is generally agreed that the drug acts at an early stage of $T$ cell activation $[1,2]$.

Since the first studies in clinical organ transplantation $[3,4]$, much interest has been shown in this drug. Recently some multicentre studies have reported encouraging results obtained on large-scale trials with cyclosporin in cadaveric renal transplantation, in comparison with those obtained with conventional therapies including azathioprine $[5,6]$.

No data, except for some preliminary reports from our group [7] and from the University of Minnesota [8], have appeared on the effects of cyclosporin in human pancreatic transplantation. It seems rational to employ cyclosporin as the immunosuppressant in pancreaticorenal transplantation in order to confirm the results obtained with other organ transplantations, and with the aim of reducing or eliminating steroids from the treatment, thus achieving a better control of carbohydrate metabolism.

At the Herriot Hospital, Lyon, the therapy of choice for Type 1 diabetic patients with end-stage renal failure consists, in the absence of related kidney donors, of double simultaneous kidney plus pancreatic transplantation from cadaveric donors. In these patients the use of cyclosporin was commenced in June 1981.

We report the results of our continuing experience (30 months) of the use of cyclosporin in clinical pancreatic transplantation, either as an initial immunosuppressant or as a replacement agent after a conventional course of immunosuppression with azathioprine, in comparison with historical control subjects of the precyclosporin era (1978-1981).

\section{Subjects and methods}

\section{Subjects}

Between September 1978 and December 1983, 33 patients received primary double simultaneous pancreatic plus kidney transplantations from cadaveric donors. They all had Type 1 diabetes complicated by end-stage renal failure due to nephropathy. Their mean \pm SEM age was $35.8 \pm 1.5$ years, and their mean duration of diabetes $20 \pm 1$ years. Twenty-eight patients $(85 \%)$ were on maintenance dialysis at the time of transplantation, with a duration of dialysis of $17.0 \pm 2.3$ months. All patients were affected by severe macro- and microangiopathy, five $(15 \%)$ having undergone at least one amputation and seven $(21 \%)$ being completely blind at the time of transplantation.

Donors were heart-beating cadavers, matched with the recipients on the basis of ABO-compatibility and negative cross-match. The 
Table 1. Status on 31 December 1983 of 33 simultaneous pancreatic plus renal transplantations performed between September 1978 and December 1983

\begin{tabular}{|c|c|c|c|c|}
\hline $\begin{array}{l}\text { Protocol of } \\
\text { immunosuppression }\end{array}$ & $\begin{array}{l}\text { No. of } \\
\text { patients } \\
\text { alive }\end{array}$ & $\begin{array}{l}\text { No. of } \\
\text { pancreas } \\
\text { and } \\
\text { kidneys } \\
\text { func- } \\
\text { tioning }\end{array}$ & $\begin{array}{l}\text { No. of } \\
\text { kidneys } \\
\text { only } \\
\text { func- } \\
\text { tioning }\end{array}$ & $\begin{array}{l}\text { No. of } \\
\text { pancreas } \\
\text { only } \\
\text { func- } \\
\text { tioning }\end{array}$ \\
\hline $\begin{array}{l}\text { A: Azathioprine + anti- } \\
\text { lymphocyte globu- } \\
\text { lin }+ \text { steroids }(n=8)\end{array}$ & 1 & 0 & 1 & 0 \\
\hline $\begin{array}{l}\text { B: Cyclosporin + anti- } \\
\text { lymphocyte } \\
\text { globulin } \pm \text { steroids } \\
(n=7)\end{array}$ & 4 & ${ }^{2}(25,21)$ & 1 (19) & 0 \\
\hline $\begin{array}{l}\text { C: Cyclosporin } \pm \\
\text { steroids after proto- } \\
\text { col A }(n=18)\end{array}$ & 12 & $\begin{array}{l}9 \\
(33,12 \\
8,8,8,4 \\
3,3,1)\end{array}$ & $2(11,2)$ & 1 (7) \\
\hline Total $(n=33)$ & 17 & 11 & 4 & 1 \\
\hline
\end{tabular}

Figures in parentheses represent duration of function in months
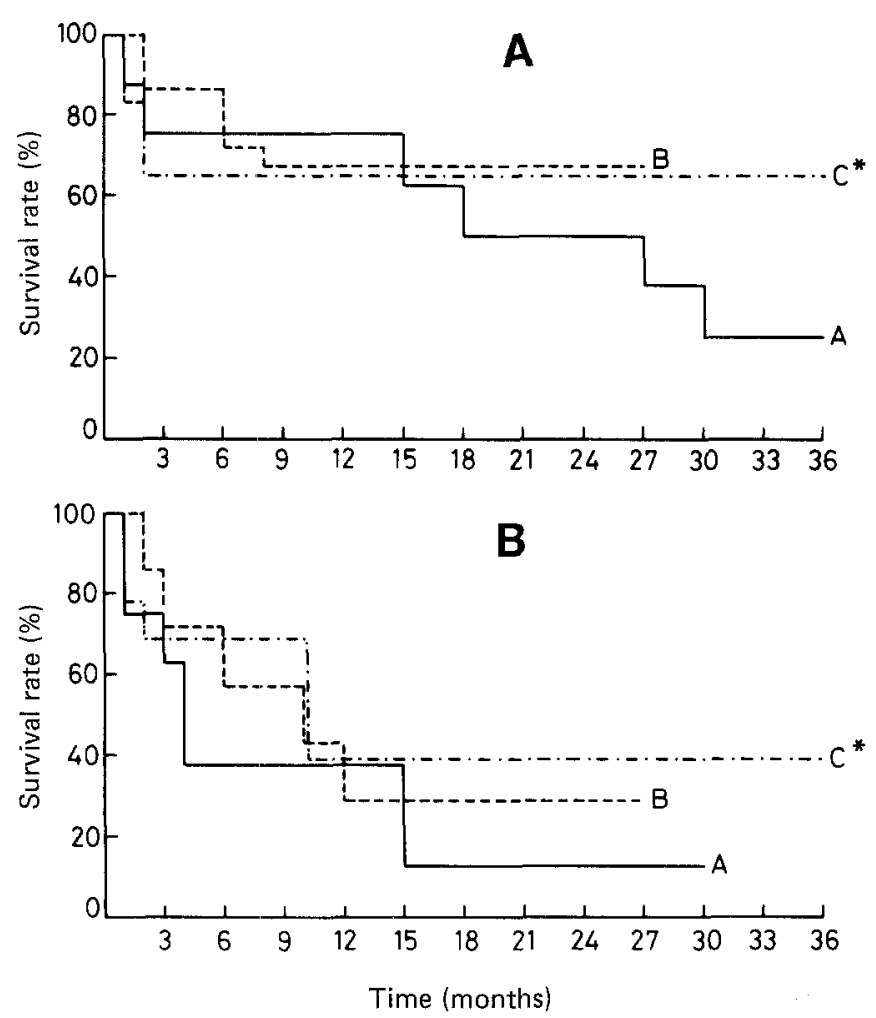

Fig. 1. A Actuarial survival rates of patients and $\mathbf{B}$ pancreatic grafts after simultaneous kidney plus pancreatic transplantation according

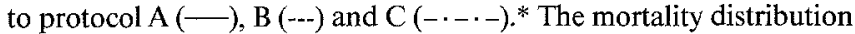
in protocol $\mathrm{C}$ was four before and two after the switching to cyclosporin

number of HLA-A and - B antigens shared between donors and recipients was none in 13 cases, one in 15 cases, two in four cases and three in one case. All patients had received deliberate blood transfusions before transplantation as immunological conditioning. The pancreatic transplantation technique has been described in detail elsewhere [9].

\section{Immunosuppression}

Three protocols of immunosuppressive therapy (A, B and C) were employed: protocol A (conventional) consisted of azathioprine and steroids associated with a temporary course of anti-lymphocyte globulins administered from the day of transplantation for 2-6 weeks. Eight patients, transplanted between September 1978 and June 1981, were treated according to this protocol. Protocol B consisted of cyclosporin administered from the day of transplantation, associated with anti-lymphocyte globulin as in protocol A. Steroids were added in case of rejection and maintained or discontinued according to the individual necessities. Cyclosporin was administered at a dose of $12-14 \mathrm{mg} \cdot \mathrm{kg}^{-1} \cdot$ day $^{-1}$ orally, and progressively tapered to maintenance doses of $4-8 \mathrm{mg} \cdot \mathrm{kg}^{-1} \cdot \mathrm{day}^{-1}$. In four cases, cyclosporin was given initially intravenously at doses of $7 \mathrm{mg} \cdot \mathrm{kg}^{-1} \cdot$ day $^{-1}$ and switched to the oral route within 7 days of transplantation. Seven patients have been treated according to this protocol since June 1981. Protocol C consisted of cyclosporin as the sole immunosuppressant, or in combination with low doses of steroid after an initial course of conventional treatment according to protocol A. The time of switching to cyclosporin ranged from 20 days to 6 months after transplantation. Eighteen patients have been treated on this protocol since June 1981. One of these patients was transplanted before that time and switched to cyclosporin as the drug became available at our institution.

\section{Analysis}

The rates of survival for patients and grafts were calculated according to the actuarial method [10].

\section{Results}

The status of patients, renal and pancreatic grafts on 31 December 1983 is summarized in Table 1 . Seventeen patients $(51 \%)$ were alive, $11(33 \%)$ with both renal and pancreatic grafts functioning, four $(12 \%)$ with only the renal graft functioning, and one with only the pancreatic graft functioning. The overall patient survival was $75 \%$ at 3 months, $67 \%$ at 6 months, $63 \%$ at 1 year, $51 \%$ at 2 years and $32 \%$ at 3 years. The overall renal graft survival was $75 \%$ at 3 months, $63 \%$ at 6 months, $51 \%$ at 1 year, $31 \%$ at 2 years and $22 \%$ at 3 years. The overall pancreatic graft survival was $62 \%$ at 3 months, $51 \%$ at 6 months, $36 \%$ at 1 year, $24 \%$ at 2 years and $12 \%$ at 3 years.

Different results were obtained with the three protocols. With protocol A the patient survival rate was $75 \%$ at 3 and 6 months and 1 year, $50 \%$ at 2 years and $25 \%$ at 3 years. With protocol $\mathrm{B}$, patient survival was $86 \%$ at 3 months, $72 \%$ at 6 months, $67 \%$ at 1 and 2 years. With protocol $\mathrm{C}$ the patient survival was $65 \%$ at 3 and 6 months, 1, 2 and 3 years (Fig. 1).

With protocol A the pancreatic graft survival rate was $63 \%$ at 3 months, $38 \%$ at 6 months and 1 year, and $13 \%$ at 2 years. With protocol B the pancreatic graft survival was $72 \%$ at 3 months, $57 \%$ at 6 months, $29 \%$ at 1 and 2 years. With protocol $C$, the pancreatic graft survival was $69 \%$ at 3 and 6 months, $39 \%$ at 1,2 and 3 years (Fig. 1).

Altogether 21 pancreatic graft failures occurred. Eleven were due to the death of the patient (three in 
protocol A, three in protocol B and five in protocol C; in the latter group, three occurred before the switch to cyclosporin), five were due to vascular thrombosis (two in protocol A, three in protocol C), and four were due to rejection (three in protocol $\mathrm{A}$ and one in protocol B).

\section{Discussion}

Although recent technical improvements have generated new interest in pancreatic transplantation, the success rate of this procedure still remains relatively low [11]. The main causes of failure are technical complications, rejection and death. Our results, although based on a relatively small number of patients, seem to indicate that the use of cyclosporin has not improved the short-term rate of success of simultaneous kidney plus pancreatic transplantation. In fact the patient and the pancreatic graft survivals at 3 and 6 months and at 1 year were similar under the three treatment protocols. In contrast, the patient and pancreatic graft survivals were improved in the cyclosporin-treated groups at 2 and, at least for protocol C, 3 years. However, this improvement cannot be attributed with certainty to cyclosporin. Indeed, the allocation of patients to different groups of therapy was not randomized and the patients treated with conventional therapy were an historical group of the pre-cyclosporin period. Therefore, additional factors other than immunosuppressive treatment, such as accumulation of experience and continuing improvements in technique, could have partially contributed to the improvement of the results. It is, nevertheless, interesting to note that among a total of 13 failures only one pancreatic graft was lost because of rejection in protocols $\mathrm{B}$ and $\mathrm{C}$, while among the eight failures with conventional therapy, three were due to rejection. Although still anecdotal, this observation might reflect a real capacity of cyclosporin to control the pancreatic rejection better.

In conclusion, our experience with cyclosporin in clinical pancreatic transplantation does not seem to be as impressive as for other organ transplantations, in agreement with the observations from the University of Minnesota [8]. This could be explained on the basis of the still relatively poor results of pancreatic transplanta- tion, due to the persisting technical problems and to the poor clinical condition of many recipients at the time of transplantation. However a decreased incidence of rejection and improved long-term survival of patients and grafts have been observed in our experience with cyclosporin. This possible positive trend can only be confirmed by further follow-up and experience.

\section{References}

1. Wagner H (1983) Cyclosporin A: mechanism of action. Transplant Proc 15: 523-526

2. Lafferty KJ, Borel JF, Hodgkin P (1983) Cyclosporin A: models for the mechanism of action. Transpl Proc 15 (Suppl 1): 2242-2247

3. Calne RY, Rolles K, White DJG, Thiru S, Evans DB, McMaster P, Dunn DC, Craddock GH, Henderson RG, Aziz S, Lewis P (1979) Cyclosporin A initially as the only immunosuppressant in 34 recipients of cadaveric organs: 32 kidneys, 2 pancreases and 2 livers. Lancet 2: 1033-1036

4. Starzl TE, Weil R III, Iwatsuki S, Klintmalm G, Schröter GPJ, Koep LJ, Iwaki Y, Terasaki PI, Porter KA (1980) The use of cyclosporin $\mathrm{A}$ and prednisone in cadaver kidney transplantation. Surg Gynecol Obstet 151: 17-26

5. The Canadian Multicentre Transplant Study Group (1983) A randomized clinical trial of cyclosporin in cadaveric renal transplantation. N Engl J Med 309: 809-815

6. European Multicentre Trial Group (1983) Cyclosporin in cadaveric renal transplantation: one-year follow up of a multicentre trial. Lancet 2: 986-989

7. Traeger J, Dubernard JM, Bosi E, Gelet A, El-Yafi S, Secchi A, Pozza G, Touraine JL (1983) Cyclosporin in clinical pancreatic transplantation. Transplant Proc 15 (Suppl 1): 2602-2605

8. Sutherland DER, Chinn PL, Goetz FC, Elick BA, Najarian JS (1983) Experience with cyclosporin versus azathioprine for pancreas transplantation. Transplant Proc 15 (Suppl 1): 2606-2612

9. Dubernard JM, Traeger J, Neyra P, Touraine JL, Tranchant D, Blanc-Brunat N (1978) A new method of preparation of segmental pancreatic grafts for transplantation: trials in dogs and in man. Surgery 84:633-639

10. Cutler JL, Ederer F (1968) Maximum utilization of the life table method in analysing survival. J Chron Dis 8: 699-704

11. Sutherland DER (1983) Pancreas transplantation: overview and current status of cases reported to the Registry through 1982. Transplant Proc 15 (Suppl 1): 2597-2601

Professor G. Pozza

Clinica Medica VIII

Istituto San Raffaele

via Olgettina 60

I-20132 Milan

Italy 